\title{
26342 - OXYGEN EXTRACTION RATIO (OER) AND BLOOD TRANSFUSION IN CARDIAC SURGERY
}

\section{Rachel O'Farrell MD, Mohammed Ghannam, BSc; McCluskey McCluskey, PhD; Scott Beattie, Keyvan Karkouti, MD; Toronto General Hospital, UHN, Toronto, ONTARIO, Canada}

INTRODUCTION: Ten to twenty percent of the blood supply in North America is cons umed during cardiac surgery, and there has been a call for urgent reevaluation of current transfusion management. To date, the decision to transfuse blood-commonly referred to as the transfusion trigger - is based primarily on a patients' hemoglobin concentration $(\mathrm{Hb})$ rather than any physiological measures of tissue oxygen consumption, which may result in over- and under-transfusion, both of which can be harmful. It has been postulated that increased oxygen extraction ratio (OER; normal range $=20-30 \%$ ), may be a more appropriate transfusion trigger. The objective of this pilot study was to measure the relationship between OER and postoperative RBC transfusions in cardiac surgery.

METHODS: Following REB approval, consecutive patients undergoing complex cardiac surgical procedures were recruited in this observational study. Prospective, detailed perioperative data were collected on all patients, including arterial and mixed venous blood gases before and $15 \mathrm{~min}, 2 \mathrm{hrs}$, and $4 \mathrm{hrs}$ after postoperative red blood cell (RBC) transfusions. OER was calculated as follows: $[((\mathrm{Hb} \times 1.36 \times \mathrm{SaO} 2)+(0.0031 \times \mathrm{PaO} 2))$ $-((\mathrm{Hb} \times 1.36 \times \mathrm{SvO} 2)+(0.0031 \times \mathrm{PvO} 2))] /[((\mathrm{Hb} \times 1.36 \times \mathrm{SaO} 2)+(0.0031 \times \mathrm{PaO} 2))]$. Changes in OER from pre to $15 \mathrm{~min}, 2 \mathrm{hrs}$, and $4 \mathrm{hrs}$ after RBC transfusion were measured and were compared using the paired t-test.

RESULTS: Of the 80 recruited patients, 40 received RBC transfusions perioperatively, with complete OER data being available on 15 of these 40 patients. Characteristics, perioperative course, and baseline $\mathrm{Hb}$ of patients with normal or elevated pre-transfusion OER were similar. OER decreased at 2 hours after RBC transfusion only in those with elevated baseline OER (see Table 1).

DISCUSSION: This pilot study suggests that elevated OER may be a more appropriate transfusion trigger than low $\mathrm{Hb}$ concentration and its use may reduce inappropriate transfusions. In this cohort, $40 \%$ of transfusions would have been avoided if elevated OER was used as the transfusion trigger. Large, prospective studies of transfusion algorithms based on elevated OER are required to determine the appropriateness of elevated OER as a transfusion trigger.

REFERENCES: 1.Ann Thorac Surg 2004 77: 626-34, $\quad$ 2.JAMA 1988 260: 27003,3.Anesthesiology 1998 88: 327-33

Table 1.

\begin{tabular}{|c|c|c|c|c|c|}
\hline OER group & Pre $\mathrm{Tx} \mathrm{Hb}$ & Post Tx Hb & $\triangle$ OER $_{\mathrm{ts} \mathrm{mn}}$ & $\triangle O E R_{2 n}$ & $\triangle O E R_{41}$ \\
\hline $\begin{array}{l}\leq 30 \%(\mathrm{~N}=6) \\
>30 \%(\mathrm{~N}=9)\end{array}$ & $\begin{array}{l}76 \pm 6 \mathrm{gl} \\
73 \pm 9 \mathrm{gl}\end{array}$ & $\begin{array}{l}85 \pm 8 \mathrm{gL} \\
78 \pm 7 \mathrm{gL}\end{array}$ & $\begin{array}{l}+3=3 \% \\
-3 \pm 5 \%\end{array}$ & $\begin{array}{l}+1=3 \% \\
-8 \pm 11 \%\end{array}$ & $\begin{array}{l}+2=6 \% \\
-8=14 \%\end{array}$ \\
\hline
\end{tabular}

